\title{
Gene signatures in wound tissue as evidenced by molecular profiling in the chick embryo model
}

\author{
Fabienne Soulet ${ }^{1,2 \dagger}$, Witold W Kilarski ${ }^{1,2 \dagger}$, Philipp Antczak ${ }^{3 \dagger}$, John Herbert ${ }^{3}$, Roy Bicknell ${ }^{3}$, Francesco Falciani ${ }^{3}$, \\ Andreas Bikfalvi ${ }^{1,2^{*}}$
}

\begin{abstract}
Background: Modern functional genomic approaches may help to better understand the molecular events involved in tissue morphogenesis and to identify molecular signatures and pathways. We have recently applied transcriptomic profiling to evidence molecular signatures in the development of the normal chicken chorioallantoic membrane (CAM) and in tumor engrafted on the CAM. We have now extended our studies by performing a transcriptome analysis in the "wound model" of the chicken CAM, which is another relevant model of tissue morphogenesis.

Results: To induce granulation tissue (GT) formation, we performed wounding of the chicken CAM and compared gene expression to normal CAM at the same stage of development. Matched control samples from the same individual were used. We observed a total of 282 genes up-regulated and 44 genes down-regulated assuming a false-discovery rate at $5 \%$ and a fold change $>2$. Furthermore, bioinformatics analysis lead to the identification of several categories that are associated to organismal injury, tissue morphology, cellular movement, inflammatory disease, development and immune system. Endothelial cell data filtering leads to the identification of several new genes with an endothelial cell signature.

Conclusions: The chick chorioallantoic wound model allows the identification of gene signatures and pathways involved in GT formation and neoangiogenesis. This may constitute a fertile ground for further studies.
\end{abstract}

\section{Background}

Different physiological as well as pathological conditions trigger tissue remodeling including surgery, infection, chemical or physical burns, ischemia or immunological reaction [1]. The restoration of tissue integrity involves alteration in tissue elasticity, interstitial fluid pressure and oxygen tension, which is normalized by vascularization of the affected region [2]. Revascularization is accomplished by the ingrown of the granulation tissue (GT) that is composed of a dense network of enlarged vessels forming specific and leaky temporary vasculature [3]. When not disturbed, GT vasculature is normalized during course of scarification. The healing process proceeds according to that general pattern e.g. in the skin but also during regenerative healing after brain or myocardium stroke [4]. Wound healing can be perturbed by

\footnotetext{
* Correspondence: a.bikfalvi@angio.u-bordeaux1.fr

+ Contributed equally

${ }^{1}$ INSERM, U920, 3340 Talence, France

Full list of author information is available at the end of the article
}

pathological changes that include ulceration, hypertrophic scaring or keloids formation and fibrosis [5]. Modern therapy requires the targeting of drugs directly to the site of interest and to accomplish that goal in systemic treatment, the molecular signatures distinguishing the expanding vasculature of the GT from the normal vessels need to be known.

The chicken embryo model has been widely used in developmental biology to understand vascular development and to test the effect of molecules predicted to interfere with the angiogenic process or lymphangiogenesis [6]. For example, the effect of flow on vessel ontology such as venous or arterial patterning has been elucidated using the chicken chorioallantoic membrane (CAM) [7]. Furthermore, the effect of different angiogenesis stimulators such as VEGF-A, VEGF-C or inhibitors has been tested in the chick embryo. Adult wound healing involves movement from the epidermis and connective tissue and the recruitment of inflammatory and immunocompetent cells. Embryonic wound healing also 
involves wound contraction, followed by re-epithelialization but without recruitment of immunocompetent cells. The inflammatory response in wound healing is crucial for fighting infection so that tissue damage does not lead to death through septicaemia. But, aside from this role, recruitment of leukocytes may more negatively impact wound healing. Indeed, knockout and knockdown studies suggest that immun cells do not promote wound healing and their depletion can even enhance it $[1,8]$. Thus, models of embryonic wound healing will evidence gene regulations that are crucial for the healing process and independent from the perturbation induced by immunocompetent cells. However, neutrophile-like inflammatory cells and monocyte-like cells are accumulated in growth factor-stimulated CAM which may participate in the wound healing process [9].

Kilarski et al. [10] have developed a method to investigate GT formation in the CAM. This model has allowed a better understanding of the formation of the vasculature during GT formation [10]. The major advantages of CAM wound healing model is that the CAM is composed of blood vessels and enclosed within 2 layers of epithelium and a fibroblast matrix. This is in contrast to a skin model, for example, where there are multiple cell and tissue types (epidermis, dermis and subdermis). Wound healing in the CAM model reflects primary changes in vasculature and in stromal fibroblasts that is not affected by "noise" from other cell types. Furthermore, a matched control can be obtained from the same CAM.

Modern functional genomics approaches may facilitate a better understanding of the molecular events involved in tissue morphogenesis and allow the identification of molecular signatures and pathways. We have recently applied transcriptomic profiling to elucidate the molecular signatures involved in the development of the normal chicken chorioallantoic membrane and in tumors engrafted onto the CAM $[11,12]$. Furthermore, engraftment of human tumour tissue onto the CAM, followed by transcriptomic analyses with both human and chicken microarrays, enables the gene signatures of both the host stroma and the human tumour to be distinguished. We have now extended our earlier studies by performing a transcriptome analysis in the "wound model" of the chicken CAM. This has allowed us to identify gene signatures involved in GT formation and neoangiogenesis. These results further indicate that the chicken embryo model is an excellent tool for discovering networks that are associated with granulation-tissue formation and tissue repair.

\section{Results and Discussion}

\section{Wound induction in the chicken CAM}

Chick embryos were cultured for 10 days and CAMs were inflicted by parallel scalpel superficial cuts of $1 \mathrm{~cm}$ area, followed with a subsequent scarping off of the epithelium of the injured chorioallantoic membrane. The wound area was then covered with $1.5 \mathrm{~cm}$ square nylon grid (figure 1A). As seen in figure 1B, significant GT was formed and grew through the nylon grid in response to injury. This GT contained a significant amount of blood vessels with abnormal morphology (tortuous blood vessels). Newly formed blood vessels within the CAM became functional since injection of Indian ink clearly evidenced newly perfused blood vessels in the GT (figure 1C).

The CAM wound model has been established to analyze GT formation and the role of invading fibroblasts and blood vessels in this process [10]. It has been found that tissue tension generated by activated fibroblasts or myofibroblasts during wound contraction, mediated and directed translocation of the vasculature. This vasculature can be expanded secondarily by elongation and vessel enlargement, and finally, through splitting and sprouting. To verify the presence of myofibroblasts in our experimental set up, we performed immunohistology using anti- $\alpha 2$-somooth muscle actin antibodies. The invasion of $\alpha 2$-smooth muscle ( $\alpha 2-\mathrm{SM})$ actin positive myofibroblasts and of blood vessels in the wounded area was clearly visible and is depicted in figure 2 .

Other chick wound models that have been proposed such as epithelial regeneration models at the surface of the embryo such as at the wing bud or the midbrain region $[8,13,14]$. These models have helped to characterize some of the morphological and molecular events occurring during embryonic tissue repair involving actin cable assembly and the Rho kinases $[8,14]$. Tissue wound contraction is present in this model to some extent, however without the presence of $\alpha 2-\mathrm{SM}$ positive myofibroblasts [8]. Another model is characterized by the removal of only the peridermal layer. Wound closure in this model is essentially driven by the conversion of the basal layer, from monolayer to multilayer [15].

The advantage of our model is that it clearly distinguishes between preexisting and newly formed tissue and vasculature and that an ingrowth of $\alpha 2-\mathrm{SM}$ actin positive myofibroblasts is observed. Furthermore, recruitment and translocation of the vasculature in the wound area can be clearly envisioned. This allows us to perform transcriptomic analysis after wounding to establish which genes are important players in this process. 

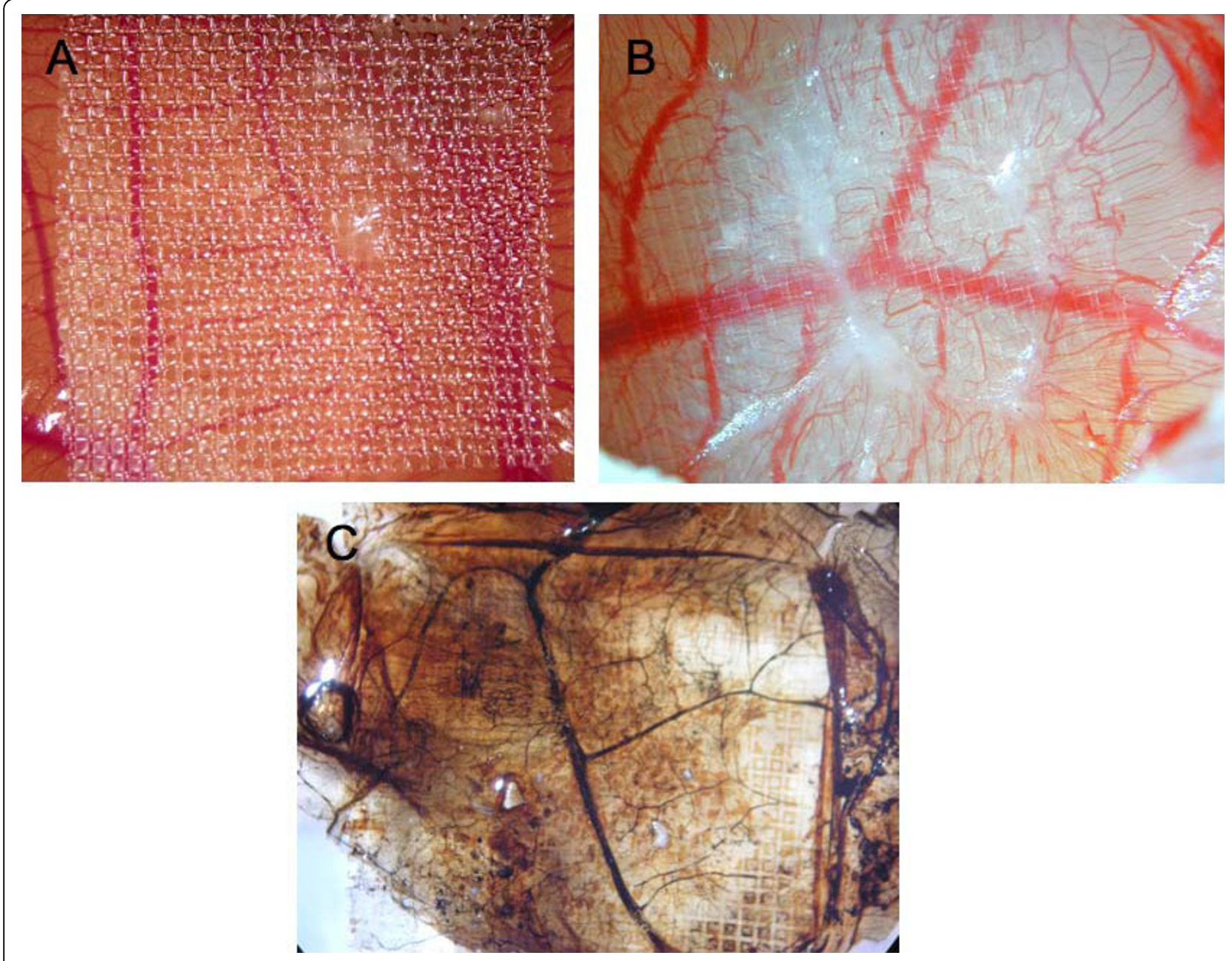

Figure 1 Wound Model of the chicken chorioallantoic membrane. Panels A and B of this figure display granulation tissue 6 days after injury ( $B$ is a larger magnification of A). In panel C, also showing granulation tissue 6 days after injury, Indian ink was injected to visualize perfused blood vessels (vessels are now black).

\section{Gene signatures in wound tissue by molecular profiling}

We therefore extracted RNA from eggs 6 days postwounding. We also extracted RNA from areas where no injury was inflicted to the CAM from the same eggs. Thus, each wound had a matched control from the same egg and three eggs were used for hybridization on each chip with their own controls (6 samples in total). Data were normalized using the robust multi-averaging method, part of the Affymetrix library in the statistical programming language R. Hierarchical clustering, performed on the three wounded and non-wounded samples, indicated separate clustering of wounded and non-wound CAM tissue (figure 3A). This indicates good quality of the samples collected and of hybridizations. We observed a total of 282 genes up-regulated and 44 genes down-regulated, applying a FDR $<5 \%$ and a fold change $>2$ (figure 3B).
Up-regulation as high as 79 fold was observed. Among the most up-regulated genes, we observed: fatty acid binding protein 4 FABP4 (79 fold), retinol binding protein 7 (RBP7) (74 fold), transthyretin (TTR) (37fold), osteopontin (SPP1) (30 fold), neutrophile cytosolic factor (NCF2) (25 fold), chemokine ah221 (LOC417536) (10 fold) and cysteine-rich secretory protein (CRISP3 (8 fold)) (Table 1). Among the most down-regulated genes, we observed: inter-alpha (globulin) inhibitor H5 (ITIH5) (0.11 fold), Collagen type VIII a1 (0.15 fold), testican (SPOCK1) (0.29 fold), Atonal homolog 8 (ATOH8) (0.29 fold), laminin a1 (LAMA1) (0.32 fold), CXCL12 (0.32 fold), C1q and TNF-related protein 1 (C1QTNF1) (0.32 fold) and plexin A2 (PLXNA2) (0.33 fold) (Table 2). In order to analyze potential functional trends in the gene lists identified, we performed a functional analysis of the lists of differentially expressed genes. With the 


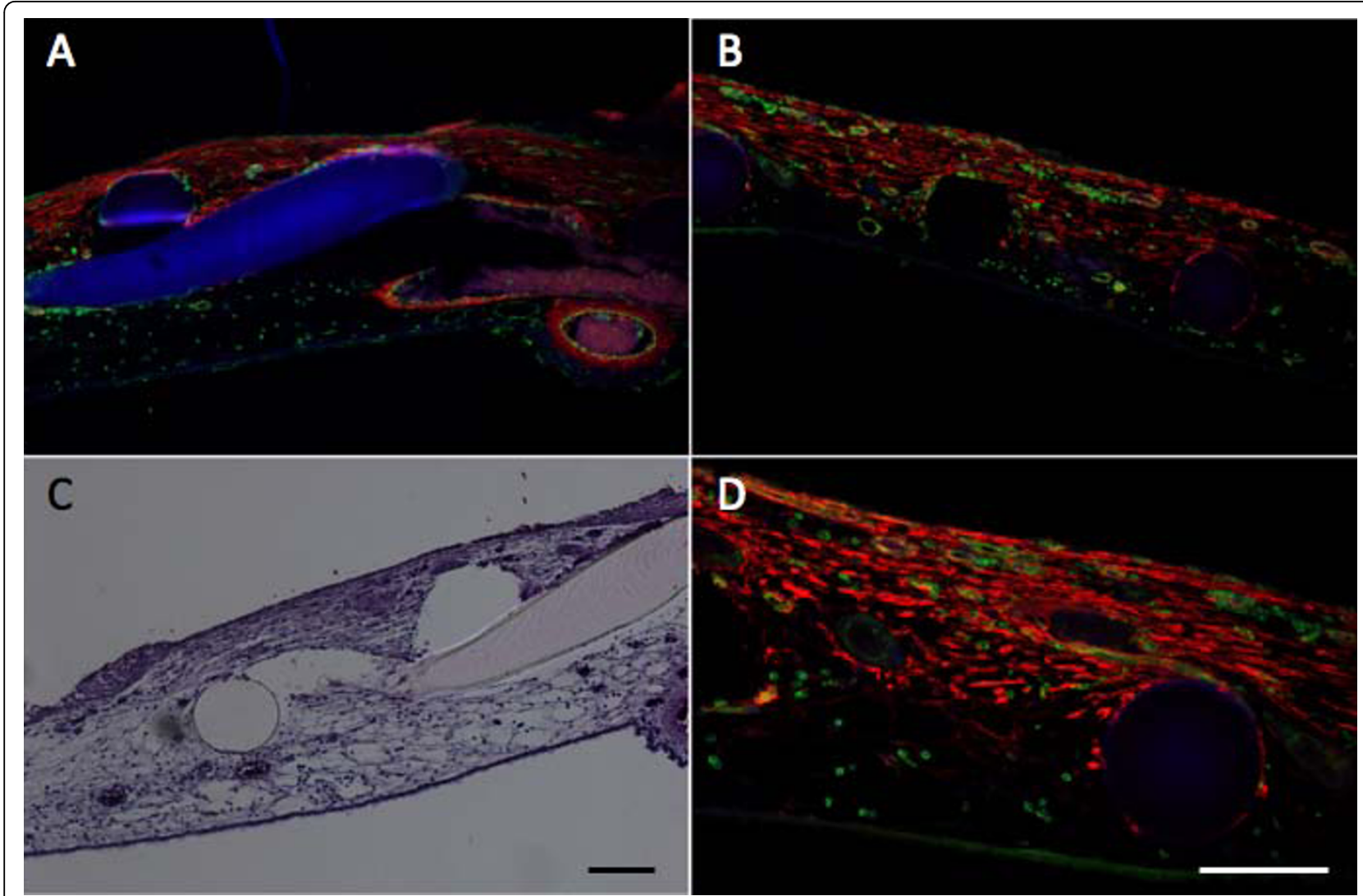

Figure 2 Histology and immunohistology in the wound model. Wounding is performed as indicated in Methods and analyzed by histology and immunohistology. Panel A and B, immunohistological analysis of $\alpha 2$-smooth muscle actin (anti- $\alpha 2-S M$ antibody) in red, vessels are stained in green (SNA-isolectin) and nuclei in blue (Dapi) of two different areas of the wounded CAM (10x magnification). Panel C, Hematoxylin-eosin staining (10X magnification. Panel $D$ is a higher magnification (20x magnification) of B. Scale bars, $100 \mu \mathrm{m}$. The figure clearly shows the infiltration of a2-SM positive myofibroblasts and of blood vessels in the wounded area. The grid is visible in blue (A), or as black (B,D) and white holes (C) or in rosa (C).

purpose to describe the overall representation of functions differentially modulated in response to wounding, we first computed the number of genes represented in the most common gene ontology (GO) categories. As seen in figure 4, the most abundant categories found in this analysis were "binding", "catalytic activity", "cell part", "cellular processes" and "metabolic processes". There was a slight preponderance of up-regulated genes within the first three categories. However, within "metabolic processes" the majority of genes were up-regulated rather than down-regulated.

Furthermore, differences in four other categories related to extracellular matrix and adhesion ("biological adhesion", "extracellular matrix", "extracellular region" and "extracellular region part") were quite striking. In these categories, down-regulated genes were much more abundant. In addition to this analysis, and in order to identify functional categories enriched in our gene lists, we also performed a functional analysis using the web based tool, DAVID [16,17]. This procedure clusters genes with similar functions (defined by similar Gene ontology or KEGG pathway terms) into annotation clusters (Additional file 1). It then assesses whether these "functional clusters" are over-represented in the list of genes differentially regulated. We submitted the up and down regulated genes separately and summarized the results in table 3 . Due to the relatively low number of significant genes at 5\% FDR level, we have also verified that results of the analysis were similar at less stringent FDR thresholds (10\% and 15\%FDR). Generally no new functions emerged when the FDR was increased but as expected, each function increased in significance and enrichment.

The expression of a number of cytokines or chemokines was up-regulated after wounding. Some of them are represented in the GO term "Cytokines-Chemokines". Among the others clearly associated with this category are IL10R, IL4R, chemokine ligand 20 (CCL20), CX3CR1 and IL1 $\beta$. Components of the major histocompatibility complex (MHC) were also found up-regulated 


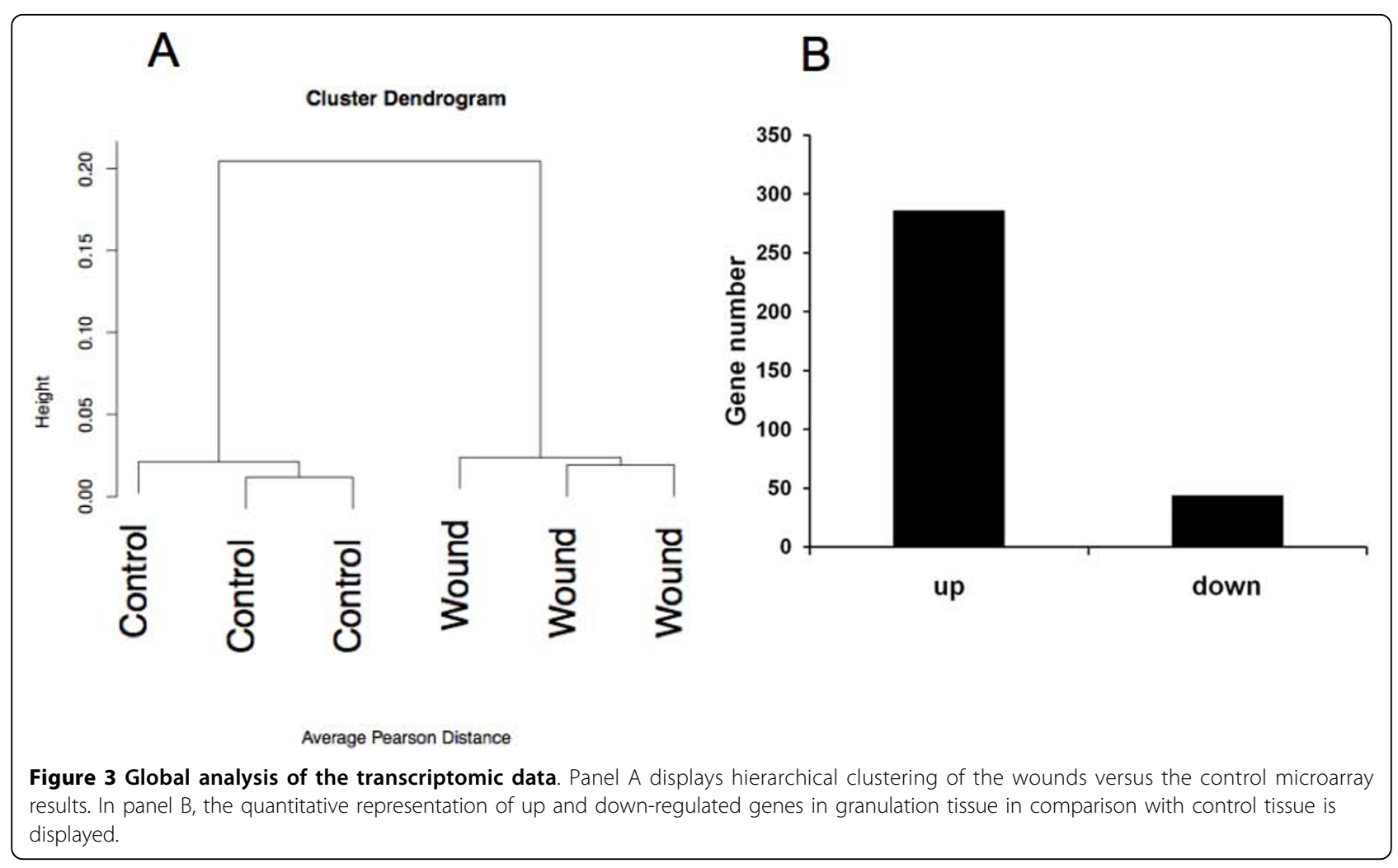

Table 1 List of $\mathbf{2 0}$ most induced genes in granulation tissue

\begin{tabular}{|c|c|c|c|c|}
\hline Affymetrix ID & $\begin{array}{l}\text { UniGene } \\
\text { ID }\end{array}$ & Gene Name & $\begin{array}{l}\text { Gene } \\
\text { Symbol }\end{array}$ & $\begin{array}{l}\text { Fold } \\
\text { Change }\end{array}$ \\
\hline Gga.4939.1.S1_s_at & Gga.4939 & fatty acid binding protein 4 , adipocyte & FABP4 & 79.23 \\
\hline Gga.9386.1.S1_at & Gga.9386 & retinol binding protein 7 , cellular & RBP7 & 73.82 \\
\hline Gga.17686.1.S1_at & Gga.41504 & keratin 75 & KRT75 & 59.38 \\
\hline Gga.2620.1.S1_at & Gga.2620 & transthyretin & $T T R$ & 36.7 \\
\hline Gga.3551.1.S1_at & Gga.3551 & $\begin{array}{l}\text { secreted phosphoprotein } 1 \text { (osteopontin, bone sialoprotein I, early T-lymphocyte } \\
\text { activation 1) }\end{array}$ & SPP1 & 30.01 \\
\hline Gga.17647.1.S1_at & Gga.34552 & neutrophil cytosolic factor 2 (65 kDa, chronic granulomatous disease, autosomal 2) & NCF2 & 25.09 \\
\hline Gga.7228.1.S1_at & Gga.7228 & carboxymethylenebutenolidase homolog (Pseudomonas) & CMBL & 14.33 \\
\hline Gga.11640.1.S1_at & Gga.11640 & succinate receptor 1 & SUCNR1 & 11.04 \\
\hline $\begin{array}{l}\text { GgaAffx.10393.1. } \\
\text { S1_at }\end{array}$ & Gga.46851 & cytochrome b-245, beta polypeptide (chronic granulomatous disease) & CYBB & 10.25 \\
\hline Gga.9133.1.S1_at & Gga.9133 & Chemokine ah221 & LOC417536 & 9.95 \\
\hline Gga.6239.1.S1_at & Gga.6239 & regulator of G-protein signalling 1 & RGS1 & 9.28 \\
\hline Gga.11456.1.S1_at & Gga.11456 & cystatin A (stefin A) & CSTA & 9.25 \\
\hline Gga.3383.1.S1_at & Gga.3383 & lipopolysaccharide-induced TNF factor & LITAF & 9.16 \\
\hline Gga.729.1.S1_at & Gga.729 & mature avidin & LOC396260 & 8.41 \\
\hline Gga.1158.3.S1_a_at & Gga.1158 & HOP homeobox & HOPX & 8.41 \\
\hline GgaAffx.6592.1.S1_at & - & - & - & 8.36 \\
\hline $\begin{array}{l}\text { GgaAffx.25031.1. } \\
\text { S1_at }\end{array}$ & Gga.19498 & cysteine-rich secretory protein 3 & CRISP3 & 8.29 \\
\hline Gga.17679.1.S1_s_at & Gga.39008 & similar to immunoglobulin-like receptor $\mathrm{CHIR-AB3}-\mathrm{B} 4$-B5 -B & LOC425449 & 8.2 \\
\hline $\begin{array}{l}\text { GgaAffx.11785.1. } \\
\text { S1_S_at }\end{array}$ & Gga.9879 & lipase A, lysosomal acid, cholesterol esterase (Wolman disease) & LIPA & 8.17 \\
\hline Gga.5743.1.S1_at & Gga.5743 & lymphocyte antigen 96 & LY96 & 8.09 \\
\hline
\end{tabular}


Table 2 List of $\mathbf{2 0}$ most down-regulated genes in granulation tissue

\begin{tabular}{|c|c|c|c|c|}
\hline Affymetrix ID & UniGene ID & Gene.Name & Gene Symbol & Fold Change \\
\hline Gga.9732.1.S1_at & Gga.43260 & inter-alpha (globulin) inhibitor H5 & ITIH5 & -9.09 \\
\hline Gga.3013.1.S1_at & Gga.3013 & collagen, type VIII, alpha 1 & COL8A1 & -6.67 \\
\hline Gga.3652.1.S1_at & Gga.3652 & C-type lectin domain family 3 , member B & CLEC3B & -4.35 \\
\hline GgaAffx.8087.2.S1_s_at & - & - & - & -4.17 \\
\hline Gga.15966.1.S1_at & Gga.35123 & ankyrin 2, neuronal & ANK2 & -3.85 \\
\hline Gga.9166.1.S1_at & Gga.9166 & Finished cDNA, clone ChEST252j10 & - & -3.57 \\
\hline Gga.16835.1.S1_at & Gga.15599 & sparc/osteonectin, cwcv and kazal-like domains proteoglycan (testican) 1 & SPOCK1 & -3.45 \\
\hline Gga.8360.1.S1_at & Gga.36205 & Atonal homolog 8 (Drosophila) & ATOH8 & -3.45 \\
\hline GgaAffx.26547.1.S1_at & - & - & - & -3.33 \\
\hline Gga.170.1.S1_at & Gga.170 & wingless-type MMTV integration site family, member $2 B$ & WNT2B & -3.33 \\
\hline Gga.6141.1.S1_at & Gga.6141 & immunoglobin superfamily, member 21 & IGSF21 & -3.33 \\
\hline Gga.12209.1.S1_at & Gga.12209 & Chromosome 4 open reading frame 31 & C4orf31 & -3.12 \\
\hline GgaAffx.24366.1.S1_at & Gga.23904 & laminin, alpha 1 & LAMA1 & -3.12 \\
\hline Gga.9513.1.S2_at & Gga.9513 & Chemokine (C-X-C motif) ligand 12 (stromal cell-derived factor 1) & CXCL12 & -3.12 \\
\hline GgaAffx.7505.1.S1_at & Gga.29269 & $\mathrm{C} 1 \mathrm{q}$ and tumor necrosis factor related protein 1 & C1QTNF1 & -3.12 \\
\hline Gga.19875.1.S1_at & Gga.23851 & plexin A2 & PLXNA2 & -3.03 \\
\hline Gga.8241.1.S1_at & Gga.8241 & transcription factor 21 & TCF21 & -2.86 \\
\hline Gga.9024.1.S1_at & Gga.43042 & chromosome 8 open reading frame 22 & C8orf22 & -2.86 \\
\hline Gga.618.1.S1_at & Gga.43121 & cytochrome P450 1A4 & CYP1A4 & -2.78 \\
\hline GgaAffx.3294.1.S1_at & Gga.37857 & similar to SYT9 protein & LOC423026 & -2.7 \\
\hline
\end{tabular}

after wounding. The latter may represent antigen presentation as a consequence to injury. This transcriptional response is not likely to be part of the immune system but may be associated to other cellular types of the GT such as endothelial cells or fibroblasts. Interestingly, the expression of some components of the extracellular matrix and genes involved in developmental processes were decreased. These include Wingless-type MMTV integration site family member 2B (WNT2B), fibrillin-1(FBN1), laminin- $\alpha 1$ (LAMA1), collagen VIII (COL8A1), FRAS1-related extracellular matrix-1 (FREM1), Cysteine-rich transmembrane BMP regulator 1 (CRIM1), Semaphorin 3G (SEMA3G) or Eph receptor A7 (EphA7). This indicates that synthesis of these components is no more required when significant GT formation has occurred. For the list of individual genes represented in our gene lists and belonging to these enriched categories, see additional files 2 and 3.

\section{Network analysis of genes modulated in response to wounding}

In order to identify the structure of regulatory networks underlying response to wounding we performed Ingenuity Pathway Analysis (IPA). IPA identifies gene interaction networks representing potential regulatory pathways by integrating lists of differentially expressed genes with a vast public domain literature database, representing several types of gene-gene interactions. Contrary to gene ontology analysis IPA networks represented gene interactions linked to specific mechanisms (e.g. transcriptional activation, protein-protein interactions, etc).

Additional file 4 summarizes the results of this analysis by listing the most significant networks identified. The Ingenuity category with the best scores (>20) were "Cardiovascular disease, organismal injury, tissue morphology" (score: 50), "Free Radical Scavenging, Cellular Movement, Hematological System Development and Function» (score: 45), «Inflammatory Disease, Respiratory Disease, Carbohydrate Metabolism » (score: 37), «Cellular Development, Hematological System Development and Function, Immune and Lymphatic System Development and Function » (score: 31), « Lipid Metabolism, Small Molecule Biochemistry, Vitamin and Mineral Metabolism » (score: 24), "Cancer, Immune and Lymphatic System Development and Function, Gene Expression »(score: 22).

The most significant networks identified with the best IPA scores are Network 1, 2, 3 and 4 (figures 5A-D). Network 1 and 2 rank top in the IPA score and reflect gene regulations involved in organismal injury, tissue morphology and cellular movement such as IL1, IL1b, ITGB2, PDGFBB, Rac, Ras, MMP9, PPAR, SERPINB2\&B5, IL1RAP or CXC3CR1. Network 3 depicts several genes that are involved in cell cycle regulation (cyclines A, E), cell movement (CD44, caspase). Network 4 involves regulations implicated in cellular development and cell-cell interactions (IL8, IL2R, IFN- $\gamma$ etc). The represented networks are associated with the production and response of cytokine components. More specifically, 


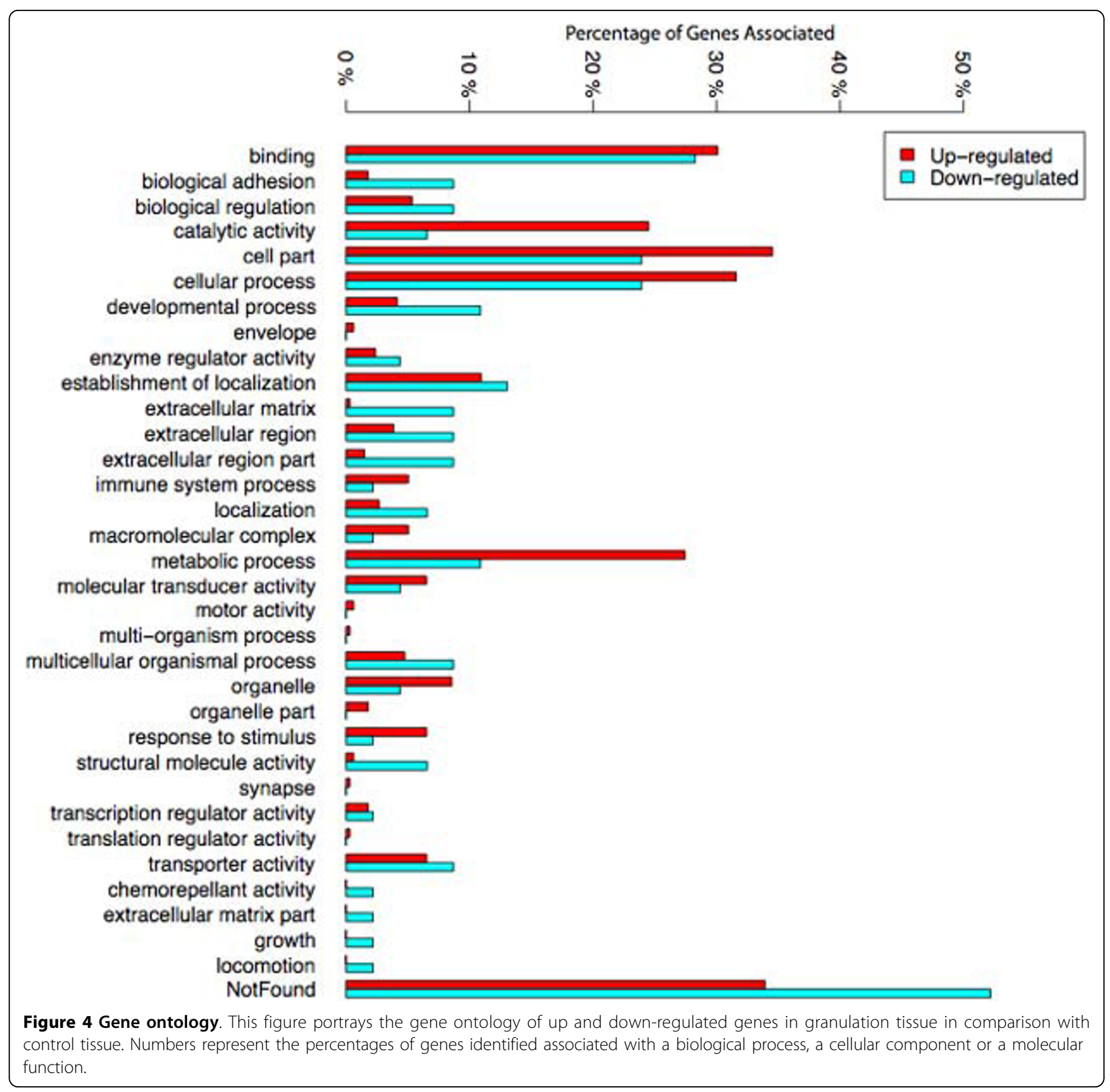

Table 3 DAVID analysis summary

\begin{tabular}{|c|c|c|c|}
\hline \multicolumn{2}{|r|}{ UP } & \multicolumn{2}{|r|}{ LO } \\
\hline $\begin{array}{l}\text { Enrichment } \\
\text { Score }\end{array}$ & Function & $\begin{array}{l}\text { Enrichment } \\
\text { Score }\end{array}$ & Function \\
\hline 4.64 & $\begin{array}{l}\text { antigen processing and presentation pf petide or polysaccharide antigen via MCH } \\
\text { class II }\end{array}$ & 2.55 & Extracellular matrix \\
\hline 2.43 & phosphoinositide binding & 1.06 & $\begin{array}{l}\text { Developmental } \\
\text { process }\end{array}$ \\
\hline 2.28 & transmembrane & & \\
\hline 1.9 & Cytokine/chemokine activity & & \\
\hline
\end{tabular}

This table shows a summary of the DAVID analysis. The functional terms most representing the annotation cluster is shown in columns 2 and 4 with the respective enrichment scores in columns 1 and 3. The higher the enrichment score, the more interesting the enriched function. 


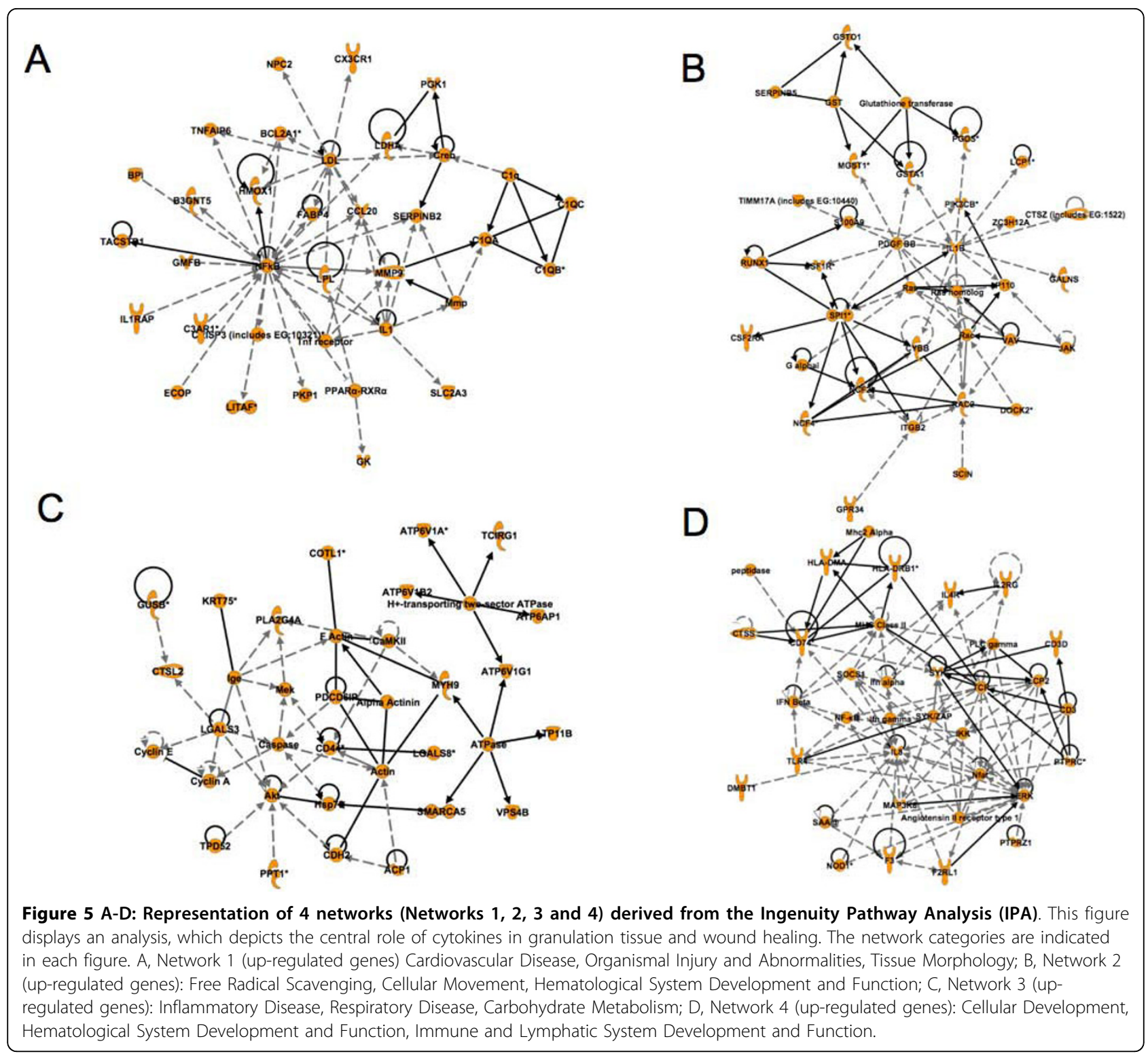

network 1 and 2 show the importance of IL-1 in the response to wounding. Our results suggest that role for this cytokine in the development of tissue repair and possibly in the onset of angiogenesis. It is known that IL-1 $\beta$ interacts with endothelial cells and induces VEGF and iNOS expression [18]. IL-1 $\beta$ also signals through IRAKs in vascular endothelial cells and induces genes in the VEGF pathway $[19,20]$. Furthermore, IL-1 $\beta$ induces fibrosis after radiation in experimental models, which indicate a possible interaction of IL-1 $\beta$ with fibroblasts [21]. In addition, IL1 $\beta$ concentrations are elevated in chronic wounds in patients [22]. Thus, IL-1 $\beta$ may regulate fibroblast proliferation and migration during GT formation. Among the other central cytokines are IL-8 and interferon- $\gamma$ (network 4 and 6 , see also additional file 5). The interaction of these cytokines with the vasculature and the stroma is well established [23,24]. Furthermore, IL- 8 expression is elevated in chronic wounds but not acute wounds, which supports a role of this cytokine in GT formation [22]. IL-8 is a powerful angiogenic chemokine implicated in vessel formation in cancer, tissue repair and inflammation. It stimulates VEGF expression and autocrine activation of VEGFR2 in vascular endothelial cells [25]. Interferon- $\gamma$ may interact with stroma fibroblasts and paradoxically negatively impact on angiogenesis [26]. It has been described that the induction of the CXC chemokine interferon- $\gamma$-inducible protein-10 (IP10) regulates the reparative response following myocardial infarction [27]. Interferon- $\gamma$ may, thus, modify the cellular composition of the healing 
tissue and promotes wound contraction, attenuating adverse remodelling.

\section{Expression analysis of some of the identified genes}

The expression of 9 of the differentially regulated genes in the Affymetrix analysis was then investigated by quantitative real-time polymerase chain reaction (qRTPCR) in wound tissue in comparison to its own control CAM (figure 6). We chose to analyze these genes because of their expression levels and because not much is known about their involvement in angiogenesis or tissue repair. Transcript levels, as determined by qPCR, were in accordance with the results obtained by the Affymetrix analysis. The respective expression levels were: FABP4 (100.5 fold), ah221 (35.4 fold), HOPX (3.3 fold), TTR (109 fold), CCL20 (37.5 fold), MSLN (5.5 fold), TCF21 (- 3 fold), ITH5 (-8.4 fold), and SPOCK1 ( -4.5 fold). Control and wound samples from 9 eggs were analyzed.

We then analyzed expression of the different genes using GenePaint http://www.genepaint.org, ProteinAtlas http://www.proteinatlas.org and Geisha http://www.geisha.arizona.edu. In GenePaint, FABP4 was expressed in the vasculature in the stage 14.5 mouse embryo. Significant staining was seen in blood vessels (figure 7A to $7 \mathrm{C}$ ), especially in the kidney (figure 7C). For comparison, the pattern of staining as seen in the kidney is identical to that of VE-Cadherin (CDH5), which is a specific marker of blood vessels (figure 7D). Furthermore, in the ProteinAtlas, staining of FABP4 was also seen in the vasculature of several organs such as the urinary bladder (figure 7E) but it is of note that not all blood vessels are stained for FABP4. There is currently only one publication describing the expression of FABP4 in the vasculature [28]. Our results are in agreement with these findings and indicate a strong expression of FABP4 after wounding. Chemokine ah221 is also significantly expressed after wounding. The human ortholog of ah221 is not yet identified but a similarity of $43 \%$ to human CCL3 is observed. CCL3 has leukocyte chemotactic activity and is involved in the recruitment of leucocytes and fibroblasts into neoangiogenic sites such as tumors [29]. CCL3 has also been shown to be produced by endothelial cells and to have an autocrine function [30]. It is likely that ah221 or its human ortholog has similar functions and plays a significant role in wound repair. HOPX is up-regulated 8.41 fold in our transcriptomic analysis. This gene is expressed during cardiac development, in various tumors, such as choriocarcinoma, and it is likely it may have a function in tissue repair as well $[31,32]$.

Transthyretin (TTR) has been found highly up-regulated in our analysis. Transthyretin (TTR) is a plasma protein mostly known for being the transporter of thyroxine and retinol $[33,34]$. When mutated, TTR is also well-described as the cause of familial amyloid polyneuropathy, a neurodegenerative lethal disorder characterized by systemic deposition of TTR amyloid fibrils [34]. A potential role in tissue repair has not yet been described for this gene but it may have an indirect effect on tissue morphogenesis

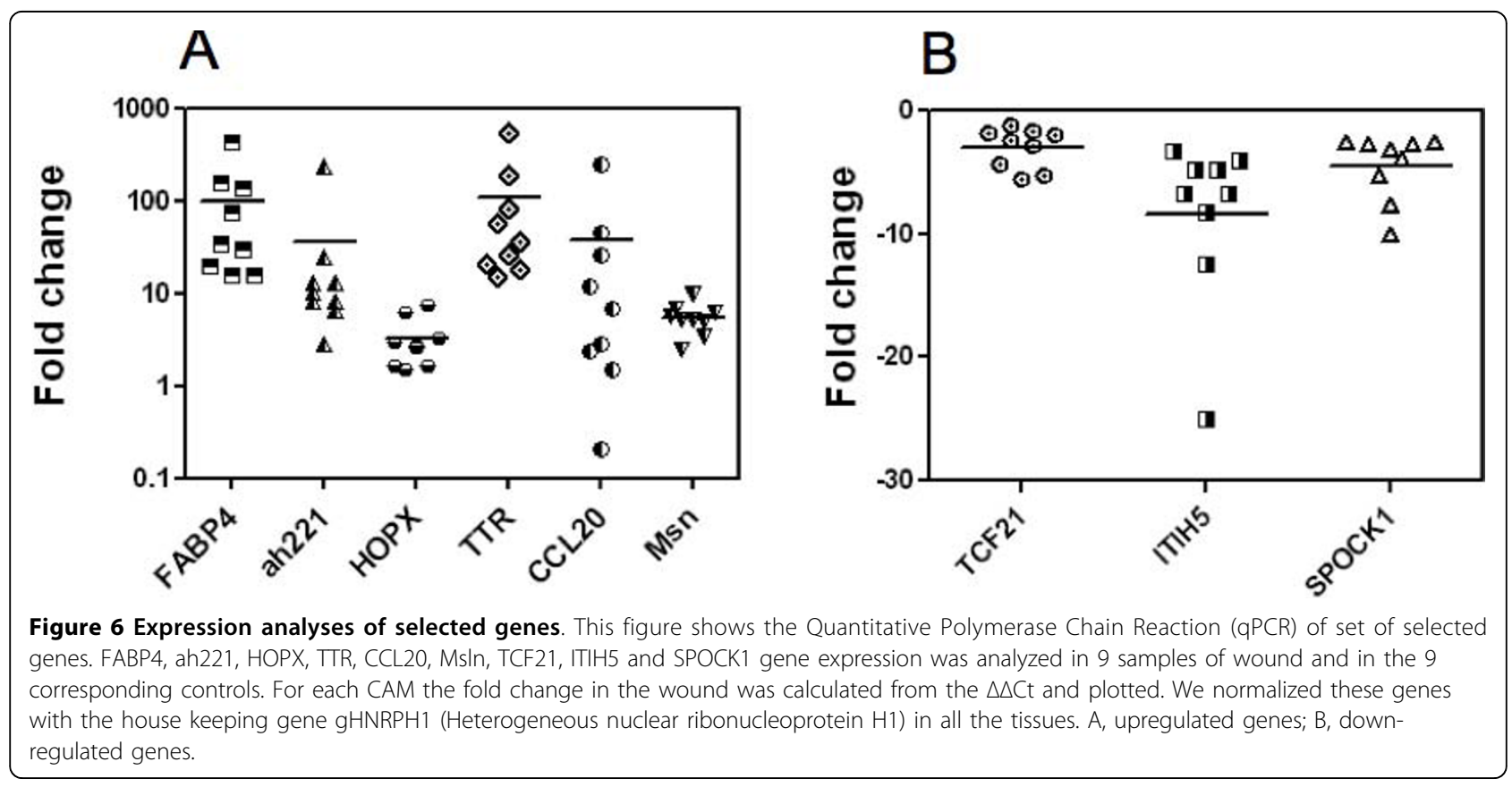




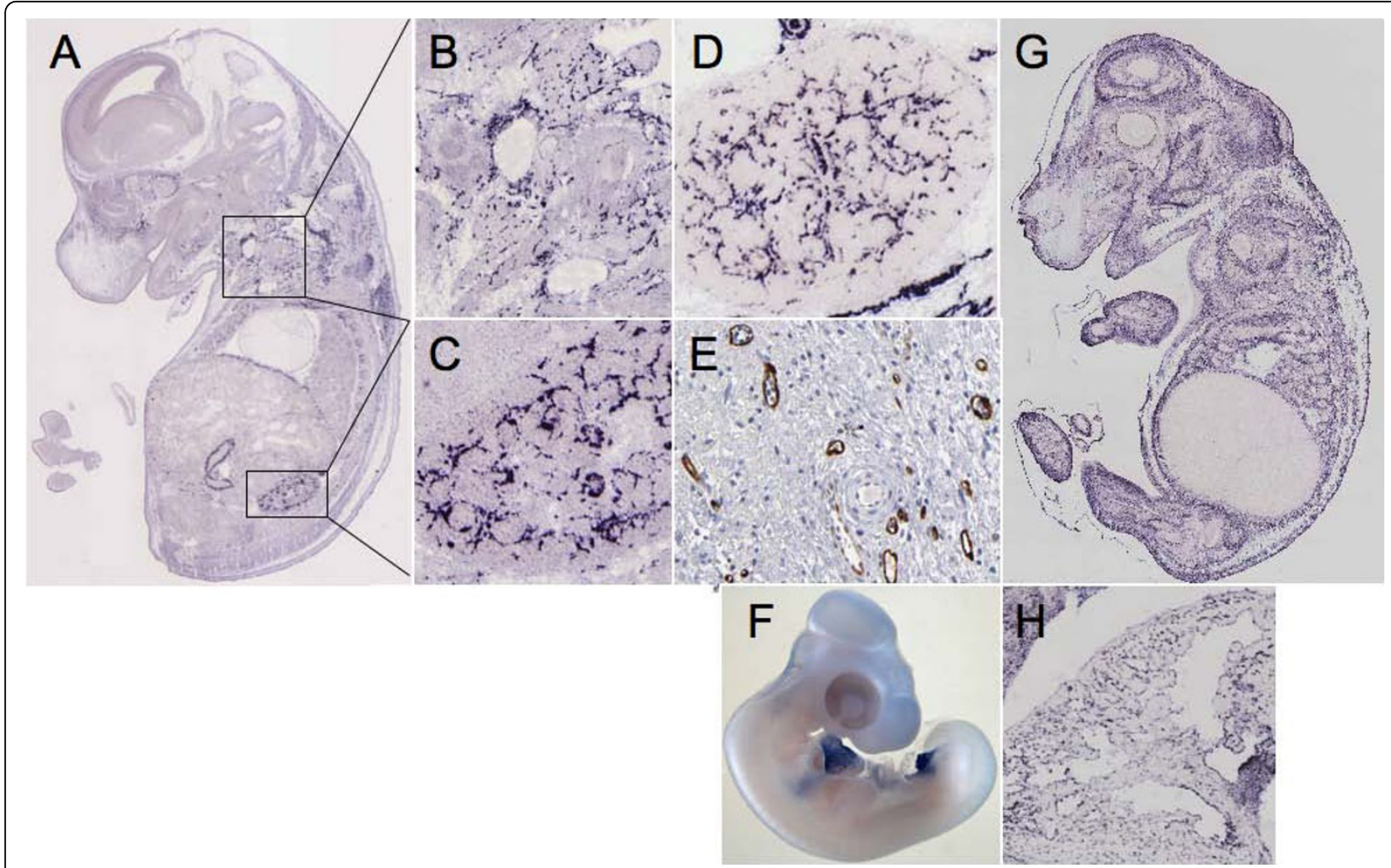

Figure 7 Analysis of selected genes by in situ hybridization. The expression patterns of FABP4, as analyzed by in situ hybridization of mouse E14.5 embryo, are displayed in panels A, B and C and the same for EMP-1 in panels F and G. Panels C and D, for direct comparison, show the expression patterns of FABP4 and CDH5 respectively in kidney. Panel E shows the expression profile of FABP4 in vessels of the urinary bladder as analyzed by immunohistochemistry. Panel G portrays the expression of EMP-1 in the endocard of an E14.5 embryo (in situ hybridization). Panel H depicts the expression of TCF21 in the E23 chick embryo (in situ hybridization).

through retinol. This is supported by our IPA (Additional file 5, Network 6) where 15 genes up-regulated in the wound are known to be directly induced by retinoic acid.

CCL20 (MIP-3 $\alpha$ ) is a CC chemokine family member that is highly expressed in our wound transcriptomic analysis. CCL20 activates CCR6 and leads to calcium mobilization and elevated active RhoA, phosphorylated myosin light chain, and F-actin accumulation and stimulation of epithelial cell migration [35]. Furthermore, in rat models of oral wound healing, CCL20 is up-regulated during the peak phase of wound healing [36]. These findings, together with ours, support an important role of this chemokine in wound healing.

Mesothelin (MSLN) is also significantly up-regulated after wounding. This is surprising since MSLN up-regulation is mainly found in mesothelioma, pancreatic, breast and ovarian carcinoma, and tumors of the GI tract http://www.proteinatlas.org. In normal tissue, significant expression is only observed in the fallopian tube http://www.proteinatlas.org. It has been shown that MSLN can interfere with cell cycle regulators by activating ERK kinase and decreasing BIM [37]. Furthermore, an increase in Stat3 activation and cyclin E in MSLN transfected pancreatic tumor cells is observed [38]. As in tumors, MSLN may promote GT formation by promoting proliferation of stromal fibroblasts and vascular cells.

TCF21, which is decreased by 3 fold in our qPCR analysis, has been implicated in kidney and lung organogenesis [39]. TCF21 -/- die in the early perinatal period because of multiple renal defects. TCF21 has also been described as a tumor suppressor gene that undergoes epigenetic modifications [40]. TCF21 has been implicated in myofibroblast differentiation and control of proliferation in mesenchymal progenitor cells [41]. During development, TCF21 is expressed at various sites in the chick embryo such as the pericardium or the allantois (figure 7H). During wound healing, TCF21 may be implicated in the regulation of fibroblast proliferation and differentiation in the GT. Inter- $\alpha$ globulin inhibitor 5 (ITIH5) decreased by 8.4 fold in our qPCR analysis, encodes one of the heavy chains of ITI, It is a protease inhibitor associated with the extracellular matrix and contributes to matrix stability by covalent linkage to 
hyaluronan. Loss of expression has been observed in various human solid tumors [42]. Furthermore, its loss by promoter hyper-methylation is associated with poor prognosis in mammary carcinoma [43]. During wound healing, this molecule is possibly involved in matrix remodeling. SPOCK1/SPARC/Osteonectin/testican-1 is decreased by 4.5 fold in our qPCR analysis. This molecule is a proteoglycan able to inhibit proteases such as MMP2 or Catepsin L [44]. SPOCK1 is also expressed in cancer associated fibroblasts where it reflects EMT [45]. However, SPOCK1 by itself inhibits angiogenesis, enhances tumor stroma formation and prevents fibroblast activation [46]. This may further explain its antitumor effect. Down-regulation of SPOCK1, as observed in our study, may contribute to an increase in vessel ingrowth and fibroblast activation during GT formation.

\section{In silico-endothelial data filtering}

Herbert and coll. have developed a method to assign endothelial cell signatures to genes identified after gene profiling studies [47]. Endothelial cell data filtering evidenced several genes with significant endothelial cell signature (Table 4). For FABP4, despite the fact that endothelial transcript counts were not high, differences were significant because no counts were observed in the non-endothelial cell pool. As indicated previously, vascular endothelial cell expression of this molecule is very pronounced. For example, FABP4 is found in the vasculature at E14.5 (figure 7B).

The molecule with the highest endothelial transcript counts was epithelial membrane protein-1 (EMP1). EMP1 was induced in our transcriptomic analysis by about 3.3 fold in the GT after wounding. In GenePaint, expression of EMP1 was seen in vascular cells and possibly in the mesenchyme (figures $7 \mathrm{~F}$ and $7 \mathrm{G}$ ). Expression is much more diffuse than that of FABP4. EMP-1 is however, highly expressed in the endothelial cell lining of the endocard (figure 7G). There is only one single publication that reports EMP1 to be present at tight junctions in vascular endothelial cells [48]. This observation fits well with a role of EMP1 in tissue repair, since endothelial cell junctions are remodeled during endothelial cell migration in the GT.

Another gene highly expressed in endothelial cells was MYCT1. MYCT1 is a direct target of c-myc and phenocopies many of the effects of c-myc $[49,50]$. It has been described to be over-expressed in gastric carcinoma [51]. No publications with regard to endothelial cell expression of this gene have been reported, which is reflected by a surprisingly low Angioscore.

CCL20 exhibited a significant Endofactor and a high Angioscore. It has been reported that endothelial cells in culture express CCL20 upon thrombin stimulation [52]. CCL20 seems to be implicated in endothelial celllymphocyte interaction through CCR6 [53]. Lymphatic endothelial cells have been reported to express CCL20 upon induction by lipoteichoic acid (LTA) [54]. However, there have been reports where expression of CCL20 is outside the vasculature, such as in tumor cells [55]. The reason for these differences is not known but genome instability of tumor cells, leading to aberrant CCL20 expression, could be the reason.

\section{Integration into a general mechanism of wound repair and granulation tissue formation}

From our results, some hypothesis can be formulated of how identified genes may fit into a general scheme of wound repair and GT formation. Tissue repair- is

Table 4 Endothelial cell data filtering

\begin{tabular}{|c|c|c|c|c|c|c|c|}
\hline Gene & qvalue & Endo Count & Non-Endo & Endo factor & Up/Down & Angioscore & Fold change \\
\hline EMP1 & 0.00 & 136 & 30 & 19.90593 & Up & 1 & 3.33 \\
\hline CD74 & 0.00 & 6 & 819 & 0.032169 & down & 10 & 6.28 \\
\hline MYCT1 & 0.00 & 16 & 0 & $\infty$ & Up & 0 & 0.4 \\
\hline CCL20 & 0.00 & 8 & 0 & $\infty$ & Up & 35 & 2.13 \\
\hline LCP1 & 0.00 & 1 & 60 & 0.073184 & down & 1 & 4.37 \\
\hline HLA-DPB1 & 0.00 & 0 & 42 & 0 & down & 2 & 4.56 \\
\hline PGD & 0.00 & 13 & 10 & 5.708318 & Up & 10 & 2.52 \\
\hline GSTO1 & 0.00 & 14 & 13 & 4.728784 & Up & 2 & 4.3 \\
\hline LTA4H & 0.00 & 9 & 5 & 7.903825 & Up & 0 & 2.55 \\
\hline FABP4 & 0.01 & 4 & 0 & $\infty$ & Up & 6 & 79.23 \\
\hline RGS1 & 0.01 & 4 & 0 & $\infty$ & Up & 6 & 9.28 \\
\hline CAP1 & 0.01 & 34 & 68 & 2.195507 & Up & 0 & \\
\hline MGST1 & 0.01 & 0 & 28 & 0 & down & 4 & 2.56 \\
\hline CD44 & 0.01 & 22 & 37 & 2.610873 & Up & 60 & 5.62 \\
\hline
\end{tabular}

The table depicts a list of genes with positive Endo factor. Genes are listed according to q-values. Fold changes derived from the transcriptomic analysis and the Angioscore are also indicated. 
driven by positively and negatively acting factors. Early ingrowth of vessels and fibroblasts are driven through growth factors and cytokines such as IL8, IL1 and PDGFRB. Some additional chemokines including CCL20 or ah221 may also contribute to endothelial cell activation, vessel remodeling during wound healing and fibroblast recruitment. FABP4 may participate in wound repair by promoting endothelial cell proliferation. EMP1 may be involved in the modulation of intercellular adhesion in vessels after endothelial cell activation and participate in the mobility and sprouting of vessels in the GT.

The expression of several matrix or matrix-associated proteins (CL8A1, FBN1, Laminin- $\alpha$ 1, FRAS-1, ITIH5 etc.) is likely to be modulated during wound repair and is decreased when significant GT formation had occurred. Down-regulation of SPOCK1, as observed in our study, may contribute to an increase in vessel in growth and fibroblast activation during GT formation. During wound healing, TCF21 may be implicated in the regulation of fibroblast proliferation and differentiation in the GT, and ITIH5 is possibly involved in matrix remodeling. Interferon- $\gamma$ may interact with stroma fibroblasts and modify the cellular composition of the healing tissue, thus, promoting wound contraction, attenuating adverse effects on remodeling.

It is possible that vitamin A has a role in wound healing [56] as it is interesting that three genes out of the top four up-regulated in the wounded CAM (from 36 fold to 79 fold up-regulation) from this study are potentially retinol related (FABP4, RBP7 and TTR). It has been shown that TTR (Transthyretin) forms a complex with Retinol Binding Protein (potentially RBP7 here) for transport of retinol around the circulation [57]. In addition, retinol binding proteins have already been shown to be differentially expressed in GT [58]. Retinol is a precursor to retinoic acid, which acts as a steroid hormone, targeting nuclear receptors of genes involved in tissue morphogenesis [59]. It is possible this steroid hormone could be delivered to cells bound to a RBP7TTR complex and be transported through the cell membrane by FABP4. FABP4 could also deliver retinoic acid to signalling molecules such as Retinoic acid receptors (RARs), Peroxisome Proliferator-Activated Receptors (PPARs) and nuclear response elements. Fatty acid binding proteins have been previously shown to do this [60]. This hypothesis is supported by previous work that found the topical addition of retinoic acid, derived from retinol, to genetically diabetic mice improves wound healing [61] and that corneal endothelial healing rates increase in the presence of retinoic acid [62]. The participation of other molecules such as Mesothelin is more difficult to envision because of lack of sufficient functional data.
There have been several studies that report transcriptomic profiling in wound tissue in different experimental settings. These include, for example, the transcriptomewide analysis in excisional murine cutaneous wound inflammation [63] or in chronic ischemic wounds in the pig model [64]. These studies are different to ours because they are performed in an immunocompetent setting and, thus, do not address exclusively the role of the stromal fibroblasts and blood vessels. There has been one study that performed a transcriptome-wide analysis of blood vessels laser captured from human skin and chronic wound-edge tissue [65]. However, in this case contamination by circulating mononuclear cells can also not not be excluded. There have also been transcriptomic profiling studies using models of tissue regeneration such as regeneration of Xenopus laevis hindlimbs [66] or fin regeneration in the medaka fish [67]. These studies are different from ours because myofibroblast invasion does not occur in these models. Our study is complementary to these existing transcriptome profling studies and provides additional informations on the gene networks implicated in wound repair and GT formation.

\section{Conclusion}

The CAM wound model has been established to analyze GT formation and the role of invading fibroblasts and blood vessels in this process [10]. It has been found that tissue tension generated by activated fibroblasts or myofibroblasts during wound contraction, mediated and directed translocation of the vasculature. This vasculature can be expanded, secondarily by elongation and vessel enlargement, and finally through splitting and sprouting. We report herein a complete transcriptome analysis of the "wound model" in the chicken CAM, which allowed the identification of gene signatures involved in GT formation and neoangiogenesis. Cytokines and chemokines clearly play a central role as evidenced in our analysis. The limitation of our work is that, contrary to the adult organism, our model is devoid of immunocompetent cells [68]. However, it has been described that MMP-9 positive neutrophile-like inflammatory cells and MMP-13 positive monocyte-like cells are accumulated in growth factor-stimulated CAM [9]. Thus, these cells may also participate, besides blood vessels and stromal fibroblasts, in GT formation after wounding in the CAM.

Another possible limitation is the relevance of our findings for the mammalian setting. Indeed, it is known that some of the regulators identified in the mammalian system that are involved in vascular development are not present in the chick such as the VE-statins [69]. However, this is a general problem for every model organism including murin models. As an example, 
CXCL4L1 is only expressed in man, mouse and chimpanzee. CXCL4L1 is a potent angio-inhibitory chemokine that has potent inhibitory activity across species. Furthermore, our laboratory has performed molecular profiling studies using human xenograft tissue in the chick CAM and identified gene regulatory mechanisms relevant for the mammalian setting $[12,70]$. Thus, we believe, that our results are of importance to the general understanding of GT formation and tissue repair.

\section{Methods}

\section{Tissue wounding}

Brown Leghorn eggs were cultured at $38^{\circ} \mathrm{C}$ for 3 days. The shells were then cracked and the contents transferred to $10 \mathrm{~cm}$ cell-culture Petri dishes. Embryo culture was continued for a another 7 days, when two injuries to the CAM were inflicted by parallel scalpel superficial cuts of $1 \mathrm{~cm}$ area, with a subsequent scarping off the epithelium of the injured chorioallantoic membrane. The wound area was then covered with $1.5 \mathrm{~cm}$ square nylon grid and after 6 days, the CAM tissue (control and wound) were excised and processed for subsequent analysis.

\section{RNA isolation}

Total RNA from cells or snap-frozen tissues were extracted byusing RNeasy mini kit (Qiagen, Courtaboeuf, France). RNA quality and quantity were assessed by agarose gel electrophoresis and optical density measurement. First strand cDNA was prepared from $1 \mu \mathrm{g}$ of total RNA with Quantitect Reverse Transcription kit (Qiagen). For all samples, a negative control was realized with mRNA without reverse transcriptase in the reaction mixture.

RNA was isolated from control and "wound" CAM 6 days after injury. Three eggs were used for independent transcriptomic profiling. It is important to note that from each egg, unwounded control CAM and wound were analyzed. RNA was isolated according to standard procedures and hybridized to Affymetrix chicken GeneChips using the Affymetrix standard protocol (Affymetrix UK Ltd, High Wycombe, UK).

\section{Transcriptome analysis}

RNAs hybridized to Affymetrix chicken GeneChips using the Affymetrix standard protocol (Affymetrix UK Ltd, High Wycombe, UK). The chicken GeneChip covers 32773 transcripts, corresponding to $>28000$ chicken genes, and has a probe set oligonucleotide length of 25 and a detection sensitivity of 1:100000 http://www.affymetrix.com. Data were analyzed with the GCOS 1.2 software (Affymetrix), using the default analysis settings; global scaling as first normalization method, with a trimmed mean target intensity value (TGT) of each array arbitrarily set to 100 .
Gene expression profiles were identified using twoclass Significance Analysis of Microarrays (SAM) method [71] (http://www-stat.stanford.edu/ tibs/SAM/, which utilizes a Wilcoxon-test statistic and sample-label permutation to evaluate statistical significance between sample groups. SAM provides mean fold change values (FC) (mean fold-change $>2$ ) and a false discovery rate (FDR) confidence percentage based on data permutation $(\mathrm{n}=200)$. The False Discovery Rate (FDR), an estimate of the fraction of selective genes, was kept below $5 \%$ in all statistical analyses.

Data analysis was done using the Gene ontology database included in the statistical environment $\mathrm{R}$ library GOstat http://www.geneontology.org and Ingenuity Pathway Analysis (IPA) (Ingenuity Systems, Redwood City, CA 94063) software. The functional clustering was performed using the method implemented on the DAVID website http://david.abcc.ncifcrf.gov/.

Annotation of genes was performed using NetAffx http://www.affymetrix.com. The microarray data files have be submitted to the US National Center for Biotechnology Information, Gene Expression Omnibus (GEO), and released in May $6^{\text {th }}, 2010$ (GEO accession number: GSE21679).

\section{qPCR analysis}

Real-time PCR was carried out in an Mx3000P thermocycler (Stratagene, La Jolla, CA) by using SYBR Green dye (ABgene, Courtaboeuf, France). Chicken-specific primers were designed and respectively evaluated for amplification efficiency using total RNA isolated from a total chicken embryo on embryonic day 5 . Only primers pairs with amplification efficacy between 90 and 100\% were used. The PCR specificity was verified by dissociation curve analysis and agarose gel electrophoresis of the amplification product.

The primer sequences are: gah221 forward CTGGCCCTCTGCTCCTCA and reverse GGACGGGACGTTGAACATAG, gCCL20 forward CGGAAGGTCATTAAGGGC and reverse AAACCATATCACA TTGACATCCTC, gFABP4 forward AGACTGCTACCTGGCCTGAC and reverse GCCATCTTCCTGGTAGCAAA, gHOPX forward GCAGTCACGCTGG CTATAAA and reverse CCATTTCTCCTGGATGGTG, gITIH5 forward TCTTGTTGCCCTTGGAAATC and reverse TTCTTTCCTCCCACCTCCTT, gMsln forward AAAATGAACAGGCTGCTGCT and reverse TCAGGC TGTTGGGGTCTATC, gSPOCK1 forward AAAGCAGGGGACCGTTAGTT and reverse TTCCAAATCATCCAGCAACA, gTCF21 forward CCATCCAG TCAACCTGACCT and reverse AGCGGTTTGTGTTCACCACT, gTTR forward TTGATTCCAAATGCC CTCTC and reverse TAGCAAAGTCCTGCCAGGTT and the house keeping gene gHNRPH1 forward 
GCTGTGTCTGCCACGAGTTA and reverse GCT TTCGGCTGAGAGACAAT.

\section{Predicting human ortholog of chicken genes}

To concentrate on genes of importance to human pathology and physiology, human orthologs of the chicken genes present on the Affymetrix chicken GeneChips were predicted using a Reciprocal Best Hit (RBH) approach [72]. In this work, both human and chicken Refseq nucleotide and protein sequences were downloaded from the NCBI on $30^{\text {th }}$ January $2008 \mathrm{ftp}: / / \mathrm{ftp}$. ncbi.nih.gov/refseq. Likewise, cDNA accession numbers of sequences used to design the microarray probes were extracted from Affymetrix chicken chip file "Chicken. na22.annot.csv" http://www.affymetrix.com. Each cDNA sequence, depending on the source of the probe design, was downloaded from ENSEMBL or the NCBI, and, as most of the cDNA sources were Expressed Sequence Tags, full length chicken mRNAs were sought by BLAST searching each of them against the Refseq chicken nucleotide database. The resulting matches were ranked as good, reasonable or bad, depending on the alignment quality (Good: sequence alignment $>100$ base pairs with a percent identity $>=96 \%$. Reasonable: a sequence alignment $>100$ bases and a percent identity $>90 \%$ and $<=95 \%$. Bad: all other hits). The full length chicken mRNA sequences ranked good and reasonable were then used in a RBH analysis.

\section{Defining chicken endothelial cell genes using human orthologs and human CDNA library analyses}

To identify which chicken genes could have an endothelial cell expression signature, the human orthologs were compared with the results from a novel in-silico bioinformatics screen, where an accurate EST-to-gene assignment and a new likelihood ratio statistic were used to find genes preferentially expressed in endothelial cells using cDNA library analyses (see Herbert et al. 2008 for a full description). The intersection of the comparison were endothelial genes and only those genes [47] with a q-value $<=0.01$ were considered. An "Endofactor" describes how significant a gene was endothelial as found with the q-value.

\section{Literature scanning of human-chick orthologs: "Angioscore"}

For all the genes found differentially expressed on the chicken chip, a literature search of the human orthologs of chicken genes were carried out to find those having literature relating to relevant pathologies and physiologies. To accomplish this, Perl scripts were written that searched article abstracts for the following keywords typical of angiogenic research. They were "angiogenic", "angiogenesis", "neovascularis(z)ation", "vasculogenesis", "vascular", "VEGF", "hypoxia" and "endoth" (for endothelial or endothelium).

\section{Expression analysis}

In situ hybridization and immunostaining data were retrieved from the Genepaint data base (Max-PlanckInstitute of Biophysical Chemistry, Dept. Genes and Behavior, 37077 Goettingen Germany; http://www. genepaint.org; figure 7A to 7D, F and 7G), Proteinatlas (AlbaNova University Center at the Royal Institute of Technology, Stockholm, Sweden, the Rudbeck Laboratory, Uppsala University, Uppsala, Sweden and Lab Surgpath, Mumbai, India; http://www.proteinatlas.org; figure 7E) and the GEISHA database (University of Arizona, Tucson, AZ 8572; http://geisha.arizona.edu [73]; figure 7F).

\section{Histology and Immunohistology}

Wound areas were fixed for at least 24 hours in a Znfixative [74]. Tissues were embedded in paraplast, and section of $10 \mu \mathrm{m}$ with a MICROM HM325 were performed and placed onto Super Frost slides. Dewaxed slides were either stained with Weigert's hematoxylin and eosin or incubated $40 \mathrm{~min}$ at $95^{\circ} \mathrm{C}$ in a citrate buffer for the antigen recovery before immunohistochemistry. These slides were then fixed with $4 \%$ paraformaldehyde, permeabilized with Triton-X100 (0.1\%), saturated with $5 \%$ BSA in PBS (pH 7.4) and incubated with the primary antibody over-night at $4{ }^{\circ} \mathrm{C}$ (anti-human Smooth Muscle actin, DAKO, IR611) This antibody also recognizes very well the chicken protein. Secondary fluorescent antimouse antibody was from Molecular Probes (used at1:1,000, Invitrogen). Chick blood vessels were visualized by using fluorescein-coupled Sambucus nigra lectin (SNA-1 lectin, 1:100, Vector Laboratories). Cell nuclei were visualized by DAPI (Invitrogen). Microphotographs were taken with a Nikon eclipse E600 microscope equipped with a digital camera Nikon DS-Ri1.

\section{List of abbreviations}

ATOH8: Atonal hololog 8; CCL: chemokine (CC motif) ligand; CXCL: chemokine (C-X-C motif) ligand; CAM: chorioallantoic membrane; C1q: Complement factor 1q; CRISP3: cysteine-riche secretory protein; EMP1: epithelial membrane protein-1; FABP4: fatty acid binding protein-4; GT: granulation tissue; HOPX: Homeobox PX; ITIH5: inter-a (globulin) inhibitor H5; LAMA1: laminin a1; LTA: lymphotoxin alpha; MSLN: mesothelin; MYCT1: myc target-1; NCF2: neutrophile cytosolic factor; PLXNA2: plexin A2; RBH: reciprocal Best Hit; RTBP7: retinol binding protein 7; SPP1: osteopontin; SPOCK1: sparc/osteonectin, cwcv and kazal-like domains proteoglycan (testican); C1QTNF1: TNF related factor-1; TCF21: transcription factor 21; TTR: 
transthyretin; TGT: trimmed mean target intensity value.

\section{Additional material}

\section{Additional file 1: (additional Table S1): Clustering of genes with similar function according to Gene Ontology terms \\ Additional file 2: (additional Table S2): List of all up-regulated genes (cut off $>2$ ).}

Additional file 3: (additional Table S3): List of all down-regulated genes (cut off $>0.1$ ).

Additional file 4: (additional Table S4): Ingenuity pathway analysis Regulated genes were analyzed by Ingenuity pathway analysis (IPA) in order to determine functional categories. Functional categories are listed in the tables that depict categories for up-regulated (A) or downregulated genes (B). As it can been seen in the tables, categories related to tissue morphological processes have the highest Ingenuity scores.

Additional file 5: (additional Figure S1A-J): Representation of networks from the IPA for up-(A-H) or down-regulated genes (I-J).

\section{Acknowledgements}

This work was supported by grant from the Agence Nationale de la Recherche (ANR, EGC) to AB. WK was supported by a fellowship from the Lefoulon-Delalande Foundation.

\section{Author details}

'INSERM, U920, 3340 Talence, France. ${ }^{2}$ Université Bordeaux I, 33405 Talence, France. ${ }^{3}$ Institute of Biomedical Research, University of Birmingham, Birmingham, B15 2TT, UK.

\section{Authors' contributions}

WK did CAM experiments, FS did expression analysis, PA and FF did bioinformatics analysis, $\mathrm{JH}$ and RB did the endothelial and Angioscore screens, $A B$ supervised the work and wrote the manuscript. All authors read and approved the final manuscript.

\section{Authors' information}

WK and FS have been post-doctoral fellows in the AB laboratory, PA is PhD student in the FF laboratory, JH is bioinformatics officer in the RB laboratory, $\mathrm{RB}$ is Professor in the division of Immunity and Infection at the Institute for Biomedical Research at the University of Birmingham Medical School (UK), $\mathrm{FF}$ is senior lecturer at the School of Biosciences at the University of Birmingham (UK), $A B$ is Professor in cell and molecular biology at the university Bordeaux and director of the molecular angiogenesis laboratory of the National Institute for Health and Medical Research (INSERM, France).

Received: 5 February 2010 Accepted: 14 September 2010 Published: 14 September 2010

\section{References}

1. Martin P, Leibovich SJ: Inflammatory cells during wound repair: the good, the bad and the ugly. Trends Cell Biol 2005, 15(11):599-607.

2. Tomasek JJ, Gabbiani G, Hinz B, Chaponnier C, Brown RA: Myofibroblasts and mechano-regulation of connective tissue remodelling. Nat Rev Mol Cell Biol 2002, 3(5):349-363.

3. Singer AJ, Clark RA: Cutaneous wound healing. N Engl J Med 1999, 341(10):738-746

4. Virag J, Murry CE: Myofibroblast and endothelial cell proliferation during murine myocardial infarct repair. The American journal of pathology 2003, 163(6):2433-2440

5. Menke NB, Ward KR, Witten TM, Bonchev DG, Diegelmann RF: Impaired wound healing. Clin Dermatol 2007, 25(1):19-25.

6. Ribatti D: Chick embryo chorioallantoic membrane as a useful tool to study angiogenesis. Int Rev Cell Mol Biol 2008, 270:181-224.
7. Jones EA, le Noble F, Eichmann A: What determines blood vessel structure? Genetic prespecification vs. hemodynamics. Physiology (Bethesda) 2006, 21:388-395.

8. Redd MJ, Cooper L, Wood W, Stramer B, Martin P: Wound healing and inflammation: embryos reveal the way to perfect repair. Philosophical transactions of the Royal Society of London 2004, 359(1445):777-784.

9. Zijlstra A, Seandel M, Kupriyanova TA, Partridge JJ, Madsen MA, HahnDantona EA, Quigley JP, Deryugina El: Proangiogenic role of neutrophillike inflammatory heterophils during neovascularization induced by growth factors and human tumor cells. Blood 2006, 107(1):317-327.

10. Kilarski WW, Samolov B, Petersson L, Kvanta A, Gerwins P: Biomechanical regulation of blood vessel growth during tissue vascularization. Nat Med 2009, 15(6):657-664.

11. Javerzat S, Franco M, Herbert J, Platonova N, Peille AL, Pantesco V, De Vos J, Assou S, Bicknell R, Bikfalvi $A$, et al: Correlating global gene regulation to angiogenesis in the developing chick extra-embryonic vascular system. PLoS One 2009, 4(11):e7856.

12. Saidi A, Javerzat S, Bellahcene A, De Vos J, Bello L, Castronovo V, Deprez M, Loiseau H, Bikfalvi A, Hagedorn M: Experimental anti-angiogenesis causes upregulation of genes associated with poor survival in glioblastoma. International journal of cancer 2008, 122(10):2187-2198.

13. Lawson A, England MA: Surface ectodermal wound healing in the chick embryo. Journal of anatomy 1998, 192(Pt 4):497-506.

14. Martin P, Lewis J: Actin cables and epidermal movement in embryonic wound healing. Nature 1992, 360(6400):179-183.

15. Armstrong MT, Turlo K, Elges CJ, Dayton SM, Lee J, Armstrong PB: A novel form of epithelial wound healing of the embryonic epidermis. Experimental cell research 2006, 312(13):2415-2423.

16. Huang da W, Sherman BT, Lempicki RA: Systematic and integrative analysis of large gene lists using DAVID bioinformatics resources. Nat Protoc 2009, 4(1):44-57.

17. Dennis G Jr, Sherman BT, Hosack DA, Yang J, Gao W, Lane HC, Lempicki RA: DAVID: Database for Annotation, Visualization, and Integrated Discovery. Genome Biol 2003, 4(5):P3.

18. Lu P, Li L, Liu G, Zhang X, Mukaida N: Enhanced experimental corneal neovascularization along with aberrant angiogenic factor expression in the absence of IL-1 receptor antagonist. Investigative ophthalmology \& visual science 2009, 50(10):4761-4768.

19. Song KW, Talamas FX, Suttmann RT, Olson PS, Barnett JW, Lee SW, Thompson KD, Jin S, Hekmat-Nejad M, Cai TZ, et al: The kinase activities of interleukin-1 receptor associated kinase (IRAK)- 1 and 4 are redundant in the control of inflammatory cytokine expression in human cells. Mol Immunol 2009, 46(7):1458-1466.

20. Schweighofer B, Testori J, Sturtzel C, Sattler S, Mayer H, Wagner O, Billban M, Hofer E: The VEGF-induced transcriptional response comprises gene clusters at the crossroad of angiogenesis and inflammation. Thromb Haemost 2009, 102(3):544-554.

21. Liu W, Ding I, Chen K, Olschowka J, Xu J, Hu D, Morrow GR, Okunieff P: Interleukin 1beta (IL1B) signaling is a critical component of radiationinduced skin fibrosis. Radiat Res 2006, 165(2):181-191.

22. Wiegand C, Schonfelder U, Abel M, Ruth P, Kaatz M, Hipler UC: Protease and pro-inflammatory cytokine concentrations are elevated in chronic compared to acute wounds and can be modulated by collagen type I in vitro. Archives of dermatological research 2009.

23. Koumas L, King AE, Critchley HO, Kelly RW, Phipps RP: Fibroblast heterogeneity: existence of functionally distinct Thy $1(+)$ and Thy $1(-)$ human female reproductive tract fibroblasts. The American journal of pathology 2001, 159(3):925-935.

24. Kofler S, Nickel T, Weis M: Role of cytokines in cardiovascular diseases: a focus on endothelial responses to inflammation. Clin Sci (Lond) 2005, 108(3):205-213.

25. Martin D, Galisteo R, Gutkind JS: CXCL8/LL8 stimulates vascular endothelial growth factor (VEGF) expression and the autocrine activation of VEGFR2 in endothelial cells by activating NFkappaB through the CBM (Carma3/ Bcl10/Malt1) complex. The Journal of biological chemistry 2009, 284(10):6038-6042

26. Lu Y, Yang W, Qin C, Zhang L, Deng J, Liu S, Qin Z: Responsiveness of stromal fibroblasts to IFN-gamma blocks tumor growth via angiostasis. J Immunol 2009, 183(10):6413-6421. 
27. Bujak M, Dobaczewski M, Gonzalez-Quesada C, Xia Y, Leucker T, Zymek P, Veeranna V, Tager AM, Luster AD, Frangogiannis NG: Induction of the CXC chemokine interferon-gamma-inducible protein 10 regulates the reparative response following myocardial infarction. Circulation research 2009, 105(10):973-983.

28. Elmasri $H$, Karaaslan $C$, Teper $Y$, Ghelfi $E$, Weng M, Ince TA, Kozakewich $H$, Bischoff J, Cataltepe S: Fatty acid binding protein 4 is a target of VEGF and a regulator of cell proliferation in endothelial cells. Faseb J 2009, 23(11):3865-3873.

29. Wu Y, Li YY, Matsushima K, Baba T, Mukaida N: CCL3-CCR5 axis regulates intratumoral accumulation of leukocytes and fibroblasts and promotes angiogenesis in murine lung metastasis process. J Immunol 2008, 181(9):6384-6393.

30. Ryschich E, Lizdenis P, Ittrich C, Benner A, Stahl S, Hamann A, Schmidt J, Knolle $P$, Arnold B, Hammerling GJ, et al: Molecular fingerprinting and autocrine growth regulation of endothelial cells in a murine model of hepatocellular carcinoma. Cancer Res 2006, 66(1):198-211.

31. Yamaguchi S, Asanoma K, Takao T, Kato K, Wake N: Homeobox gene HOPX is epigenetically silenced in human uterine endometrial cancer and suppresses estrogen-stimulated proliferation of cancer cells by inhibiting serum response factor. International journal of cancer 2009, 124(11):2577-2588

32. Liu F, Levin MD, Petrenko NB, Lu MM, Wang T, Yuan LJ, Stout AL, Epstein JA, Patel W: Histone-deacetylase inhibition reverses atrial arrhythmia inducibility and fibrosis in cardiac hypertrophy independent of angiotensin. J Mol Cell Cardiol 2008, 45(6):715-723.

33. Buxbaum JN, Reixach N: Transthyretin: the servant of many masters. Cell Mol Life Sci 2009, 66(19):3095-3101.

34. Fleming CE, Nunes AF, Sousa MM: Transthyretin: more than meets the eye. Prog Neurobiol 2009, 89(3):266-276.

35. Vongsa RA, Zimmerman NP, Dwinell MB: CCR6 regulation of the actin cytoskeleton orchestrates human beta defensin-2- and CCL20-mediated restitution of colonic epithelial cells. The Journal of biological chemistry 2009, 284(15):10034-10045

36. McGrory K, Flaitz CM, Klein JR: Chemokine changes during oral wound healing. Biochem Biophys Res Commun 2004, 324(1):317-320.

37. Uehara N, Matsuoka Y, Tsubura A: Mesothelin promotes anchorageindependent growth and prevents anoikis via extracellular signalregulated kinase signaling pathway in human breast cancer cells. $\mathrm{Mol}$ Cancer Res 2008, 6(2):186-193.

38. Bharadwaj U, Li M, Chen C, Yao Q: Mesothelin-induced pancreatic cancer cell proliferation involves alteration of cyclin $\mathrm{E}$ via activation of signal transducer and activator of transcription protein 3. Mol Cancer Res 2008 6(11):1755-1765

39. Quaggin SE, Schwartz L, Cui S, Igarashi P, Deimling J, Post M, Rossant J: The basic-helix-loop-helix protein pod1 is critically important for kidney and lung organogenesis. Development (Cambridge, England) 1999, 126(24):5771-5783.

40. Smith LT, Lin M, Brena RM, Lang JC, Schuller DE, Otterson GA, Morrison CD, Smiraglia DJ, Plass C: Epigenetic regulation of the tumor suppressor gene TCF21 on 6q23-q24 in lung and head and neck cancer. Proceedings of the National Academy of Sciences of the United States of America 2006, 103(4):982-987.

41. Plotkin M, Mudunuri V: Pod1 induces myofibroblast differentiation in mesenchymal progenitor cells from mouse kidney. Journal of cellular biochemistry 2008, 103(2):675-690.

42. Hamm A, Veeck J, Bektas N, Wild PJ, Hartmann A, Heindrichs U, Kristiansen G, Werbowetski-Ogilvie T, Del Maestro R, Knuechel R, et al: Frequent expression loss of Inter-alpha-trypsin inhibitor heavy chain (ITIH) genes in multiple human solid tumors: a systematic expression analysis. BMC cancer 2008, 8:25

43. Veeck J, Chorovicer M, Naami A, Breuer E, Zafrakas M, Bektas N, Durst M, Kristiansen G, Wild PJ, Hartmann A, et al: The extracellular matrix protein ITIH5 is a novel prognostic marker in invasive node-negative breast cancer and its aberrant expression is caused by promoter hypermethylation. Oncogene 2008, 27(6):865-876.

44. Bocock JP, Edgell CJ, Marr HS, Erickson AH: Human proteoglycan testican1 inhibits the lysosomal cysteine protease cathepsin L. European journal of biochemistry/FEBS 2003, 270(19):4008-4015.

45. Vered M, Dayan D, Yahalom R, Dobriyan A, Barshack I, Bello IO, Kantola S, Salo T: Cancer-associated fibroblasts and epithelial-mesenchymal transition in metastatic oral tongue squamous cell carcinoma. International journal of cancer

46. Chlenski A, Guerrero LJ, Yang Q, Tian Y, Peddinti R, Salwen HR, Cohn SL: SPARC enhances tumor stroma formation and prevents fibroblast activation. Oncogene 2007, 26(31):4513-4522.

47. Herbert JM, Stekel D, Sanderson S, Heath VL, Bicknell R: A novel method of differential gene expression analysis using multiple cDNA libraries applied to the identification of tumour endothelial genes. BMC Genomics 2008, 9:153.

48. Bangsow T, Baumann E, Bangsow C, Jaeger MH, Pelzer B, Gruhn P, Wolf S, von Melchner $H$, Stanimirovic DB: The epithelial membrane protein 1 is a novel tight junction protein of the blood-brain barrier. J Cereb Blood Flow Metab 2008, 28(6):1249-1260.

49. Rothermund K, Rogulski K, Fernandes E, Whiting A, Sedivy J, Pu L, Prochownik EV: C-Myc-independent restoration of multiple phenotypes by two C-Myc target genes with overlapping functions. Cancer Res 2005, 65(6):2097-2107

50. Rogulski KR, Cohen DE, Corcoran DL, Benos PV, Prochownik EV: Deregulation of common genes by c-Myc and its direct target, MT-MC1. Proceedings of the National Academy of Sciences of the United States of America 2005, 102(52):18968-18973.

51. Qiu GB, Gong LG, Hao DM, Zhen ZH, Sun KL: Expression of MTLC gene in gastric carcinoma. World J Gastroenterol 2003, 9(10):2160-2163.

52. Okada M, Suzuki K, Takada K, Nakashima M, Nakanishi T, Shinohara T: Detection of up-regulated genes in thrombin-stimulated human umbilical vein endothelial cells. Thromb Res 2006, 118(6):715-721.

53. Oyama T, Miura S, Watanabe C, Hokari R, Fujiyama Y, Komoto S, Tsuzuki $Y$, Hosoe N, Nagata H, Hibi T: CXCL12 and CCL20 play a significant role in mucosal T-lymphocyte adherence to intestinal microvessels in mice. Microcirculation 2007, 14(7):753-766

54. Sawa Y, Tsuruga E, Iwasawa K, Ishikawa H, Yoshida S: Leukocyte adhesion molecule and chemokine production through lipoteichoic acid recognition by toll-like receptor 2 in cultured human lymphatic endothelium. Cell Tissue Res 2008, 333(2):237-252.

55. Beider K, Abraham M, Begin M, Wald H, Weiss ID, Wald O, Pikarsky E, Abramovitch R, Zeira E, Galun E, et al: Interaction between CXCR4 and CCL20 pathways regulates tumor growth. PLoS One 2009, 4(4):e5125.

56. Theodosiou M, Laudet $V$, Schubert M: From carrot to clinic: an overview of the retinoic acid signaling pathway. Cell Mol Life Sci 67(9):1423-1445.

57. Vogel S, Piantedosi R, O'Byrne SM, Kako Y, Quadro L, Gottesman ME, Goldberg IJ, Blaner WS: Retinol-binding protein-deficient mice: biochemical basis for impaired vision. Biochemistry 2002, 41(51):15360-15368.

58. Xu G, Redard M, Gabbiani G, Neuville P: Cellular retinol-binding protein-1 is transiently expressed in granulation tissue fibroblasts and differentially expressed in fibroblasts cultured from different organs. The American journal of pathology 1997, 151(6):1741-1749.

59. Clagett-Dame M, DeLuca HF: The role of vitamin A in mammalian reproduction and embryonic development. Annual review of nutrition 2002, 22:347-381.

60. Tan NS, Shaw NS, Vinckenbosch N, Liu P, Yasmin R, Desvergne B, Wahli W, Noy N: Selective cooperation between fatty acid binding proteins and peroxisome proliferator-activated receptors in regulating transcription. Molecular and cellular biology 2002, 22(14):5114-5127.

61. Kitano Y, Yoshimura K, Uchida G, Sato K, Harii K: Pretreatment with topical all-trans-retinoic acid is beneficial for wound healing in genetically diabetic mice. Archives of dermatological research 2001, 293(10):515-521.

62. Matsuda M, Ubels JL, Edelhauser HF: Corneal endothelial healing rate and the effect of topical retinoic acid. Investigative ophthalmology \& visual science 1986, 27(8):1193-1198.

63. Roy S, Khanna S, Rink C, Biswas S, Sen CK: Characterization of the acute temporal changes in excisional murine cutaneous wound inflammation by screening of the wound-edge transcriptome. Physiological genomics 2008, 34(2):162-184.

64. Roy S, Biswas S, Khanna S, Gordillo G, Bergdall V, Green J, Marsh CB, Gould LJ, Sen CK: Characterization of a preclinical model of chronic ischemic wound. Physiological genomics 2009, 37(3):211-224.

65. Roy S, Patel D, Khanna S, Gordillo GM, Biswas S, Friedman A, Sen CK: Transcriptome-wide analysis of blood vessels laser captured from human skin and chronic wound-edge tissue. Proceedings of the National 
Academy of Sciences of the United States of America 2007, 104(36):14472-14477.

66. Pearl EJ, Barker D, Day RC, Beck CW: Identification of genes associated with regenerative success of Xenopus laevis hindlimbs. BMC developmental biology 2008, 8:66

67. Nishidate M, Nakatani Y, Kudo A, Kawakami A: Identification of novel markers expressed during fin regeneration by microarray analysis in medaka fish. Dev Dyn 2007, 236(9):2685-2693.

68. Janse EM, Jeurissen SH: Ontogeny and function of two non-lymphoid cell populations in the chicken embryo. Immunobiology 1991, 182(5):472-481.

69. Lelievre E, Hinek A, Lupu F, Buquet C, Soncin F, Mattot V: VE-statin/egfl7 regulates vascular elastogenesis by interacting with lysyl oxidases. The EMBO journal 2008, 27(12):1658-1670.

70. Dumartin L, Quemener C, Laklai H, Herbert J, Bicknell R, Bousquet C, Pyronnet S, Castronovo V, Schilling MK, Bikfalvi A, et al: Netrin-1 mediates early events in pancreatic adenocarcinoma progression, acting on tumor and endothelial cells. Gastroenterology 138(4):1595-1606, 1606 e1591-1598.

71. Pan W: A comparative review of statistical methods for discovering differentially expressed genes in replicated microarray experiments. Bioinformatics 2002, 18(4):546-554.

72. Herbert JM, Buffa FM, Vorschmitt H, Egginton S, Bicknell R: A new procedure for determining the genetic basis of a physiological process in a non-model species, illustrated by cold induced angiogenesis in the carp. BMC Genomics 2009, 10:490.

73. Darnell DK, Kaur S, Stanislaw S, Davey S, Konieczka JH, Yatskievych TA, Antin PB: GEISHA: an in situ hybridization gene expression resource for the chicken embryo. Cytogenetic and genome research 2007, 117(14):30-35.

74. Beckstead JH: A simple technique for preservation of fixation-sensitive antigens in paraffin-embedded tissues. J Histochem Cytochem 1994, 42(8):1127-1134

doi:10.1186/1471-2164-11-495

Cite this article as: Soulet et al:: Gene signatures in wound tissue as evidenced by molecular profiling in the chick embryo model. $B M C$ Genomics 2010 11:495.

\section{Submit your next manuscript to BioMed Central and take full advantage of:}

- Convenient online submission

- Thorough peer review

- No space constraints or color figure charges

- Immediate publication on acceptance

- Inclusion in PubMed, CAS, Scopus and Google Scholar

- Research which is freely available for redistribution

Submit your manuscript at www.biomedcentral.com/submit
Biomed Central 